\title{
THORAX
}

Editorials

\section{European standards for lung function testing: 1993 update}

The first report of the working party on standardisation of lung function tests set up by the European Community for Steel and Coal was published in $1983 .^{1}$ This document describes in detail most of the available tests of lung mechanics and carbon monoxide transfer, with detailed recommendations as to how they should be performed. An original feature was the compilation of summary equations based on pooled results from a number of series of reference values in normal subjects, calculated from the published regression equations.

These recommendations have been re-examined by a new working party, again led by its scientific secretary Philip Quanjer. This group has re-examined the assumptions of the 1983 document and has updated it with numerous fresh references. The whole work has now been published as a supplement to the European Respiratory fournal. ${ }^{2-5}$ Again entitled "Standardized Lung Function Testing" it consists of four sections: (1) lung volumes and forced ventilatory flows, 1993 update; (2) transfer factor (diffusing capacity), 1993 update; (3) airway responsiveness (previously covered by the guidelines of the European Society for Clinical Respiratory Physiology published in $1983^{\circ}$ ); and (4) symbols, abbreviations and units, 1993 update.

The sections on static and dynamic lung volumes and carbon monoxide transfer consist of extended essays on the physiology underlying the tests with some hints on their clinical application. These are followed by detailed recommendations as to how the tests should be performed with acceptable alternatives in some instances. The summary equations have been compared with more recent data and, in general, have been retained except for

Table 1 Generally acceptable recommendations (after Gibson) ${ }^{7}$

\begin{tabular}{lll}
\hline Heading & Recommendations & Comment \\
\hline $\begin{array}{ll}\text { Static lung } \\
\text { volumes }\end{array}$ & $\begin{array}{l}\text { Define restrictive ventilatory } \\
\text { defect as reduction of TLC. }\end{array}$ & $\begin{array}{l}\text { ATS allows reduction } \\
\text { of VC without } \\
\text { obstruction. }\end{array}$
\end{tabular}

Measure TLC by inspiring

fully immediately after

measurement of thoracic gas

volume during body

plethysmography.

Dynamic lung Report maximal expiratory

volumes flow in terms of lung volume remaining to be expired.

Measure slow VC rather than FVC in chronic airflow obstruction.
$\mathrm{MEF}_{75} / \mathrm{VC}=$ maximal expiratory flow when $75 \%$ of VC has been exhaled ( $25 \%$ remains). $\mathrm{FEV}_{1} / \mathrm{EVC}$ is a more sensitive index of obstruction than FEV 1 /FVC.

Table 2 Recommendations which may not be easy to implement (after Gibson $^{7}$ with modifications)

\begin{tabular}{lll}
\hline Heading & Recommendations & Comment \\
\hline Lung volumes & $\begin{array}{l}\text { Report inspiratory vital } \\
\text { capacity in preference to } \\
\text { expiratory vital capacity in } \\
\text { airflow obstruction. }\end{array}$ & $\begin{array}{l}\text { The widespread use of } \\
\text { wedge bellows } \\
\text { spirometers is largely } \\
\text { ignored. }\end{array}$ \\
$\begin{array}{ll}\text { Lung function } \\
\text { results }\end{array}$ & $\begin{array}{l}\text { Use of standardised } \\
\text { residuals to express } \\
\text { departures from the mean } \\
\text { reference value. }\end{array}$ & $\begin{array}{l}\text { This is the correct way } \\
\text { to express deviation } \\
\text { from "normality" and } \\
\text { could readily be } \\
\text { accepted if introduced } \\
\text { in a readable form on } \\
\text { lung function reports. }\end{array}$ \\
\hline
\end{tabular}

the equations for transfer coefficient which were invalid.

The recommendations on airway responsiveness are lucid and reflect the rapid developments in this field. Techniques for the performance of histamine, methacholine, non-isotonic, exercise, and allergen challenges are described in detail. Work on some of the newer bronchoconstrictors is reviewed.

Finally, the earlier recommendations for symbols, abbreviations and units are restated with some additions. These consist of the usual confusing combinations of upper and lower case roman and italic type. Subscripts follow the main abbreviation and are all on one line. Publishers of books will not like them because the very long subscripts make the printed page rather ugly, but they have the merit of simplicity and efficiency and are probably the best option for most journals. Reassuringly

Table 3 Recommendations which are controversial (after Gibson ${ }^{7}$ with modifications)

\begin{tabular}{lll}
\hline Heading & Recommendations & Comment \\
\hline TLCO & $\begin{array}{l}\text { Calculate TLCo as transfer } \\
\text { coefficient and alveolar } \\
\text { volume derived from TLC } \\
\text { measurement in preference } \\
\text { to single breath alveolar } \\
\text { volume. }\end{array}$ & See text \\
$\begin{array}{l}\text { Measurement of the } \\
\text { alveolar capillary blood } \\
\text { volume has some } \\
\text { relevance in clinical practice. }\end{array}$ & $\begin{array}{l}\text { Measurement of the } \\
\text { oxygen dependent and } \\
\text { independent components } \\
\text { but there is interesting } \\
\text { clinical experience in its }\end{array}$ \\
Lung & use in unselected patients. & ATS prefers to choose the
\end{tabular}

published equations closest to local normal values derived from a sample of 40 subjects. 
no attempt has been made to standardise the spelling of "standardis $(\mathrm{z}) \mathrm{e}$ ".

The recommendations of the working party have been accepted by the European Respiratory Society and the document carries the status of an official statement of the Society. Its publication has been covered by an editorial in the European Respiratory fournal by John Gibson ${ }^{7}$ in which he has picked out many of the important proposals and highlighted differences from the American Thoracic Society's recommendations. ${ }^{8-10}$ These points are summarised with some modification and comment in tables 1,2 , and 3 .

\section{Static lung volumes}

The report emphasises measurement of lung volumes at body temperature and pressure (BTPS) with appropriate facilities for measuring temperature in the exhaled gas.

There is a detailed and helpful section on the problem of calibrating pneumotachometers. For strict accuracy these devices should be calibrated separately for inspiration and expiration and for all the gas mixtures that are applicable. The compromise given is that repeated measurements of forced expiration may be made through an unheated device, provided that the instrument is not allowed to heat up gradually. Other devices such as rotating vane anemometers are noted to be used increasingly but without any comment as to their suitability or specifications. These require software to overcome the inaccuracies caused by their inertia. Like the classical devices they are governed by the general rules applying to all measuring equipment: they must be capable of external calibration and their output should be recorded or displayed graphically. The report also notes the increasing interest in methods of. measuring displacement of the thorax and abdomen but these are not discussed.

There is considerable detail about the measurement of lung volumes by helium dilution and by body plethysmography, with a brief mention of other methods. Closed circuit spirometry by helium dilution is recognised to be the routine method of choice for the determination of lung volumes, but it is accepted that the results will yield only an approximate figure in patients with airflow obstruction in whom plethysmographic or radiographic methods yield better results. Logically it might be thought that, since the majority of patients reporting for investigation in a lung function laboratory have airflow obstruction, plethysmography should be the standard device for clinical practice, but to have made this recommendation would clearly have been a counsel of perfection which could never be accepted. Closed circuit spirometry is a simple technique requiring a lower level of sophistication in construction and operation. It is easier to carry into the field in epidemiological studies. With suitable precautions it is usually possible to distinguish between obstructive and restrictive ventilatory defects. It is left to individual laboratories to decide whether, if they have a body plethysmograph, they should aim to use it as often as possible or keep it in reserve for special cases. No advice is given about the analysis of the loops generated during plethysmography.

There are recommendations for the sequence of respiratory manoeuvres to be performed in the measurement of subdivision of lung volume after the determination of functional residual capacity (FRC) or thoracic gas volume (TGV). These are quite different for the two methods. In closed circuit spirometry the determination of FRC during quiet breathing is followed by three measurements of expiratory reserve volume (ERV), the largest of which is chosen. Total lung capacity (TLC) is determined from ERV plus inspired vital capacity (IVC), measured separately after a rest. In body plethysmography the simple but inaccurate practice of measuring TGV on separate occasions and then subsequently performing a number of vital capacity manoeuvres is rightly condemned. The recommended procedure is to measure TGV and then inspire fully to TLC. TGV is to be taken $\overrightarrow{\vec{D}}$ as the mean of three or more determinations which differ $\overrightarrow{0}$ by less than $5 \%$ from the mean; TLC is mean TGV plus the largest of the inspiratory capacities derived from a TGV which is within $5 \%$ of the mean. The residual vol- $\mathbb{8}$ ume (RV) is then reported as TLC minus IVC. This \& method has been shown to work well but it leaves the $\vec{\sim}$ reader wondering why the reverse sequence is superior 9 during closed circuit spirometry. The explanation lies in $\vec{\omega}$ the fact that patients with airflow obstruction can reproducibly reach both TLC by a forceful inspiratory effort $\vec{x}$ and RV by a gentle but prolonged exhalation. The $\stackrel{\infty}{\infty}$ measurement of RV starting at TLC has to be avoided 0 because airway closure occurs at a higher volume. The advice regarding closed circuit spirometry is similar to 응 that given in 1983, with the exception that a rather inaccurate correction for the supposed uptake of helium $c$ in body fluids during rebreathing has been removed.

Throughout the report there is emphasis on the IVC $\frac{\overrightarrow{\mathbb{D}}}{3}$ which is usually the largest value in airflow obstruction. The slow expiratory vital capacity (EVC) is recommend- $\frac{\mathbb{\Phi}}{-}$ ed as a substitute where closed circuit spirometry is not $\overrightarrow{\mathscr{E}}$ performed because EVC is usually larger than forced vital $\omega$ capacity (FVC) in patients with airflow obstruction (with $\square$ the result that $\mathrm{FEV}_{1} / \mathrm{IVC}$ and $\mathrm{FEV}_{1} / \mathrm{EVC}$ are more sensitive indices of airflow obstruction than $\left.\mathrm{FEV}_{1} / \mathrm{FVC}\right)$. Elsewhere it is pointed out that the vital capacity is highly $\stackrel{\circ}{\circ}$

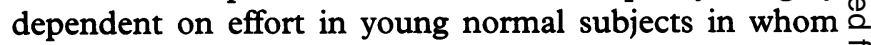
FVC is often better than EVC. My own reporting soft- $\overrightarrow{\overrightarrow{0}}$ ware chooses whichever measurement of vital capacity is largest and uses this as the denominator of the forced expiratory ratio $\mathrm{FEV}_{1} / \mathrm{VC}$.

\section{Dynamic lung volumes}

The document tidies up a number of messy details in the measurement of forced expiratory volumes and flows. $\dot{\alpha}$ The indices that may be derived from maximal expiratory and inspiratory flow volume loops are carefully defined. 음 It is pointed out that these tests, which give a revealing picture of the forced expiratory manoeuvre, have not proved really useful in epidemiological studies because of N the methodological difficulties associated with them. In particular, the derivation of flow rates when $50 \%$ and $25 \%$ of the vital capacity remains to be exhaled are criti- $\omega$ cally dependent on the ability of the instrument to detect and integrate low flow rates, since these values are falsely $\frac{0}{\Phi}$ high if expiration is incomplete.

The working party again recommended the envelope method of reporting flow volume indices by superimposing the curves at TLC and reporting the largest flow val- $\stackrel{\mathbb{Q}}{\square}$ ues at given percentages of the largest FVC. The method $\stackrel{\mathbb{\Phi}}{\varrho}$ recommended by the American Thoracic Society of reporting the best curve $\left(\mathrm{FEV}_{1}\right.$ plus FVC) is rejected as being less reproducible, although it does have the advantage that the curves can be analysed separately without the need for electronic superimposition or storage. The? document is rather dismissive of the value of a further search for perfection in this area. Theoretically the best curve has the sharpest rise to peak flow, the highest peak flow, and the longest vital capacity. It is very fatiguing for subjects to continue to make forced expiratory manoeuvres to achieve all these three criteria. In spite of the difficulties, clinicians will continue to request 
maximal inspiratory and expiratory flow volume curves because they are valuable in two contexts. Firstly, subjects with reduced peak flows show distinct patterns according to whether the obstruction is mainly central or peripheral and whether it is mainly inside or outside the thorax. Secondly, mid expiratory flow indices are a sensitive measure of minor degrees of airflow obstruction when the FVC is normal and close to the relaxed vital capacity.

Patients with severe airflow obstruction yield better results for $\mathrm{FEV}_{1}$ and mid expiratory flow rates when they make submaximal efforts, thereby avoiding airway collapse. The working party has not tackled the problem of which $\mathrm{FEV}_{1}$ to report in these individuals. My own practice is to report the figures obtained with maximal effort, with a written comment.

The detailed instructions for performing $\mathrm{FEV}_{1}$ and FVC are largely unaltered. When using a spirometer bell the starting point of the $\mathrm{FEV}_{1}$ manoeuvre is measured by backward extrapolation of the steep portion of the curve by not more than $100 \mathrm{ml}$. Eight seconds of forced expiration only are required, not 14 seconds as required by the American Thoracic Society (a source of relief to the manufacturers of portable direct writing spirometers). The requirements are sufficiently stringent to ensure that epidemiological studies which conform to these are as rigorous as possible.

For clinical purposes convenience has to be traded, to some extent, against loss of accuracy. It is sometimes suggested that clinical information does not need to be as accurate as material intended for publication but this is not always true-for example, clinical decisions regarding the treatment of pulmonary sarcoidosis currently depend on serial measurements of vital capacity. Movement between the radiographic stages is associated with changes of only $10 \%$, while most equipment is capable of measuring vital capacity with an accuracy of $5 \%$.

Considerable accuracy is also required to identify reversible airflow obstruction. The working party emphasises the importance of an absolute as well as a percentage increase, and a recommended criterion is an increase of $\mathrm{FEV}_{1}$ or FVC of greater than $12 \%$ of the predicted value and greater than $200 \mathrm{ml}$.

Measurement of peak expiratory flow is hardly mentioned as it is to be the subject of another document, but it is worth noting that an increase in peak flow of 60 $1 / \mathrm{min}$ is regarded as a criterion for reversibility of airflow obstruction.

\section{Transfer factor for carbon monoxide}

The working party has again opted for the name "transfer factor" rather than "diffusing capacity" for this test. The reasons are those originally given: that the procedure does not measure diffusion but whole lung carbon monoxide (CO) uptake, and the result is not strictly a "capacity" because it is capable of increasing-for example, in exercise or recumbency.

The working party recommends that transfer factor should be reported as the $\mathrm{CO}$ transfer coefficient in STPD units multiplied by the alveolar volume (VA) in BTPS units. This has important consequences for the reporting of transfer coefficient (TLCO/VA) because, in most studies, this is derived by calculating whole lung TLCO and dividing it by the alveolar volume either in BTPS or STPD units. Since there is a $20 \%$ difference between these, lack of standardisation has led to important misunderstandings. This was evident in the summary equations for transfer coefficient published in the 1983 document which have now been withdrawn.
Surprisingly, the original papers employed to derive the summary equations calculated TLCO/NA in a number of different ways. ${ }^{11}$ TLCO/VA is best regarded as a number which gives useful clinical information in several well defined situations such as the identification of pulmonary emphysema and the diagnosis of a chest wall or pleural component of a restrictive ventilatory defect. It is probably best to calculate the "expected" value of TLCO/VA from the expected values of its two components.

The report tackles the vexed question of the correct VA to employ in the calculation of single breath TLCO. It is recommended that the measurement should be made without undue pressure or suction at a lung volume corresponding to at least $90 \%$ of IVC. Transfer coefficient is to be multiplied by the TLC derived from another measurement such as closed circuit helium spirometry. This is the original recommended method and has the merit of ensuring that lung volumes are measured when transfer factor is to be reported, as some clinical information is lost if they are not. Nevertheless it is difficult to accept the reasoning that, because the single breath VA underestimates TLC in patients with chronic airflow obstruction, this somehow underestimates the TLCO. The advantage of calculating VA during the single breath is that TLCO can be defined in physiological terms as the carbon monoxide uptake in the ventilated portion of the lung at TLC (assuming that this is a single "effective" compartment). Since we do not know whether the inaccessible or unventilated portion of the lung is perfused or not, it seems pointless to include it in the whole lung transfer factor by assuming that it has the same vascularity as the accessible portion in which uptake is measured.

It is recognised that, for epidemiological studies, the single breath VA may be preferable. Although single breath RV is the same as multiple breath RV in normal subjects, corrections to TLC yield a consistent error in the calculation of TLCO if the breath is held at a volume lower than this. The American Thoracic Society recommends the use of the single breath VA for clinical and epidemiological purposes; most laboratories adhere to this.

The use of $17-18 \%$ oxygen in the inspired gas mixture is recommended. This yields the least variability in alveolar oxygen pressure (and also has the merit of being the cheapest option as helium and carbon monoxide can simply be added to air). The formula of Kanner and Crapo ${ }^{12}$ can be used to correct the alveolar oxygen to $16 \%$ if this is measured; surprisingly this work is not mentioned in the report. The working party prefers to correct to an alveolar value of $14.5 \%$ but does not suggest a method of calculation. It points out correctly that the validity of an alveolar gas correction has not been tested at altitude. We have found that the correction of Kanner and Crapo improves the measurement of TLCO during exercise (AH Kendrick and G Laszlo, unpublished.)

The document hints that measurement of the pulmonary blood volume may be useful clinically, which is surprising. It is pointed out that the value of theta is only an estimate.

\section{Bronchial challenge}

Bronchial challenge remains a research procedure in the UK and has a limited clinical role worldwide. This section therefore has a somewhat different status from the remainder of the standardisation document. It is a very well written and sensibly argued account of the application and usefulness of different types of bronchoconstrictor challenge. What may loosely be called bronchial hyperreactivity is quite common in healthy subjects 
(around 10\%) and is a feature of chronic airflow obstruction. Bronchial challenge testing cannot therefore be used to diagnose asthma unless a definition is used which is so stringent that it becomes very insensitive. A normal bronchial challenge has negative predictive value-that is, it excludes asthma with a high degree of probability.

Since these procedures are likely to become more widespread in the UK as elsewhere, the recommendations of the working party are useful. For safety it is suggested that the operator should always be experienced in the emergency treatment of asthma, that there should be a physician on call able to reach the scene within $10 \mathrm{~min}-$ utes, and that for antigen challenges a physician should invariably be present. Measurement of $\mathrm{FEV}_{1}$ is recommended except for research in normal subjects when sensitive but less repeatable indices such as specific airway conductance may be useful. In bronchial challenge work repeatability within subjects is of paramount importance. There are detailed accounts of how different challenges may be performed in a reproducible manner. This document refreshingly combines enthusiasm, scepticism, and sound practice; it deserves reading for its own sake, regardless of any advice about standardisation that it may contain.

\section{Benefits of standardisation}

There are a number of reasons why published standards can be helpful. These guidelines run them altogether without comment: thus, it has to be read as a whole. The main objectives are to improve reproducibility within subjects and to ensure that, if a subject visits two different laboratories on the same day, similar results will be produced. There are recommendations regarding the sequence in which tests are to performed, the minimum specification required for the equipment, and safety measures. There are suggested performance standards for equipment, and manufacturers should be able to state how far their products conform to them. Facilities for external calibration must always be provided in spite of increasing automation and computerisation. Editors and reviewers of scientific articles will enquire whether standard methods have been used and this document will provide them with a strong basis for questioning slipshod techniques.

The members of the working party have taken a generous view of the imperfections of biological measurement and of the resistance of individuals to change for its own $\stackrel{x}{.}$ sake. Editors will similarly show sympathy towards $\overrightarrow{\vec{F}}$ researchers with limited resources working under difficult $\overrightarrow{0}$ conditions whose measurements may not conform strictly $\frac{}{0}$ to European or American standards. Nevertheless, there $\frac{\bar{\rho}}{\bar{b}}$ is no point in publishing numerical results if their validity $\mathbb{\Phi}$ cannot be assessed. By avoiding dogma and, in the main, ڤ perfectionism, the working party has made a major contribution to the practice of physiological measurement in respiratory medicine.

GABRIEL LASZLO Respiratory Department, $\overrightarrow{\vec{x}}$ Bristol BS2 8HW, UK $\stackrel{+}{\infty}$

Reprint requests to: Dr G Laszlo Quanjer PhH. Standardized lung function testing. Bull Eur Physiopathol
Respir 1983;19(Suppl 5):1-95.

2 Quanjer PhH. Standardized lung function testing. Eur Respir $71993 ; 6 \stackrel{\odot}{\mathcal{C}}$ (Suppl 16):3-102s.

3 Quanjer PhH, Tammeling GJ, Cotes JE, Petersen OF, Peslin R, Yernault $\stackrel{\vec{D}}{\vec{D}}$ JC. Lung volumes and forced ventilatory flows. Eur Respir $\mathcal{f} 1993 ; 63$ (Suppl 16):5-40s.

4 Cotes JE, Chinn DJ, Quanjer PhH, Roca J, Yernault JC. Standardisation of the measurement of transfer factor (diffusing capacity). Eur Respir $\mathcal{F} \overrightarrow{0}$ 1993;6(Suppl 16):41-52s.

5 Sterk PJ, Fabbri LM, Quanjer PhH, Cockroft DW, O'Byrne PM, Anderson SD, et al. Airway responsiveness, standardized challenge testing with pharmacological, physical and sensitizing stimuli in adults. Eur ing with pharmacological, physical and sensitizing stimuli in adults. Eur
Respir $\mathcal{Y}$ 1993;6(Suppl 16):53-83s.

6 Eiser NM, Kerrebijn KF, Quanjer Ph H. Guidelines for standardization of bronchial challenges with non-specific bronchoconstricting agents. $\bar{O}$ Bull Eur Physiopathol Respir 1983;19:495-514.

7 Gibson GJ. Standardised lung function testing. Eur Respir $\mathcal{F}$ 1993;6: 155-7.

8 American Thoracic Society. Standardization of spirometry. 1987 update. $\overrightarrow{\vec{\sigma}}$ Am Rev Respir Dis 1987;136:1285-98.

9 American Thoracic Society. Single breath carbon monoxide diffusing capacity (transfer factor). Am Rev Respir Dis 1987;137:1299-307.

10 American Thoracic Society. Lung function testing: selection of reference $\frac{\vec{O}}{0}$ values and interpretative strategies. Am Rev Respir Dis 1991;144: 1202-18. 11 Williams AJ, Laszlo G. Standardised lung function testing. Thorax $\frac{\overrightarrow{0}}{19085 ; 0: 479-80 \text { (letters). }}$

12 Kanner RE, Crapo RO. The relationship between alveolar oxygen tension. and the single breath carbon monoxide diffusing capacity. Am Rev Respir Dis 1986;133:676-8. 